\title{
Modular Torque Wrench Extension with Heads-up Display
}

\author{
Atif Saeed, Mechatronic Engineering, Juan Aguirre Rodriguez, Mechatronic Engineering, \\ Juan Castano, Mechatronic Engineering \\ Vaughn College of Aeronautics and Technology, NY, USA, \\ atif.saeed@vaughn.edu,juan.castano@vaughn.edu \\ juan.aguirrerodriguez@vaughn.edu
}

\author{
Mentors: Mohammed Benalla, Ph.D., Hossein Rahemi, Ph.D. \\ Vaughn College of Aeronautics and Technology, NY, USA \\ mohammed.benalla@vaughn.edu,hossein.rahemi@vaughn.edu
}

\begin{abstract}
Torque control is a critical component of the assembly process within the manufacturing industry. Costly repairs and damages arise if it is not properly addressed. Once a product is put into service, if a fastening error is detected, it can result in severe damages to the structure and possibly even fatalities. Incorrect torqueing of a fastener can cost a manufacturer millions of dollars in repairs and liabilities. The solution to this problem is to utilize a torque wrench during the assembly process; however, based on current technology, these can be prohibitively expensive. Torque wrenches are unnecessarily bulky and have the high probability of over or under torqueing a bolt, because they rely on mechanical parts that require calibration after a period of use. A distracted user can also increase the likelihood of a fastening error. The objective of this project is to design a compact, affordable, and precise torque wrench extension with a heads-up display. This product aims to provide modularity between a variety of ratcheting wrenches and to allow the user live torque feedback displayed on safety glasses, in order to reduce the likelihood of a fastening error.
\end{abstract}

Keywords: Torque, Modularity, Heads-up, Wrench, Wheatstone, Force, Safety

\section{INTRODUCTION}

Within the aerospace manufacturing and maintenance industry, line workers manually torque bolts to a specific torque value using a digital torque wrench or frequently a manual torque wrench, Fig.1. A worker must research the specific torque value of a bolt, using an instruction manual, and set the torque wrench each time. Many discrepancies can occur in following this procedure. Incorrectly torqueing a bolt onto an aircraft can lead to a catastrophic failure of the aircraft structure, resulting in millions in damages or possibly even fatalities. With the modular torque wrench extension, along with a headsup display, line workers will have a preset torque value for a specific bolt and will be able to see the real-time torque value on their safety glasses, thus allowing for precise torque even while they remain fully aware of their environment.

Digital Object Identifier (DOI):

http://dx.doi.org/10.18687/LACCEI2020.1.1.203

ISBN: 978-958-52071-4-1 ISSN: 2414-6390

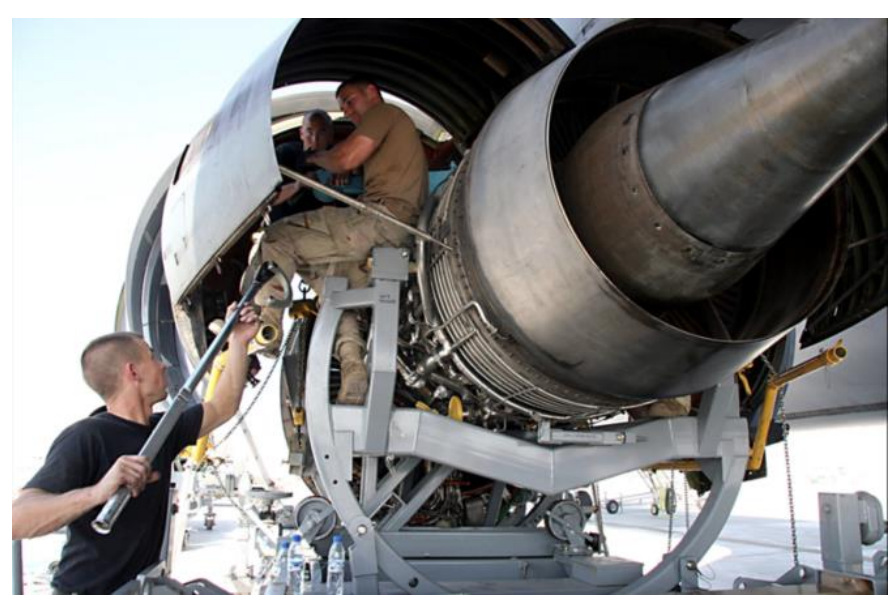

Fig. 1 Technician using Torque Wrench for Engine Change [1]

\section{A. Objective}

The objective of this project is to create a user-friendly and affordable real-time torque-sensing torque wrench along with a heads-up display. When the torque wrench is used in conjunction with the heads-up display attached to the worker's safety glasses, it allows the user to accurately and precisely torque a bolt to the required specification. Furthermore, this product prevents over and under torqueing of a bolt by highlighting key specification values through the heads-up display.

\section{B. Related Background}

In torqueing applications, the purpose is to ensure that a mechanical force constitutes the following force: clamping force, preloading force, shearing force, and tension force, Fig. 2. The clamping force is desired for creating tension between two parts to ensure that the components which the bolt was passed through remains tight and ultimately secure. The preloading force is responsible for creating the ideal no-slip condition involving the threads of the bolt and the nut. The turning of the bolt causes the threads to "catch" onto the bolt, due to friction and stretch, as more torque is applied. The sheer force is the force that is transverse to the long axis of the bolt and can be present when the bolt is in tension or not. Finally,

$18^{\text {th }}$ LACCEI International Multi-Conference for Engineering, Education, and Technology: "Modular Torque Wrench Extension with Heads-up Display", July 27-31, 2020, Virtual Edition. 
the tension force is the internal force experienced by the bolt along the long axis that correlates with the stretching of the bolt as it is turned.

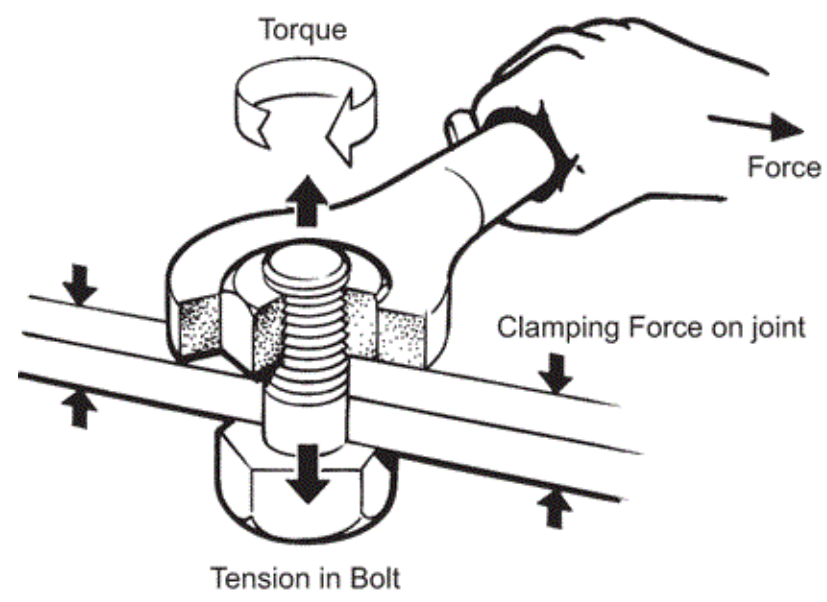

Fig. 2 Force Diagram of Bolt Torqueing [2]

There are various methods to torque down a bolt. The torque control tightening method is most commonly implemented. The technique is based on using tables or by calculation from the determination of the relationship between the torsional stress and the bolts yield stress, as shown in Table I. Although commonly used, this method sometimes permits improper torqueing, due to variances in the friction from bolt to bolt (rust can affect friction), which greatly affects the preload of a bolt.

TABLE I

TORQUE CONTROL TIGHTENING [3]

\begin{tabular}{|c|c|c|c|c|c|c|c|c|c|c|}
\hline 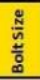 & $\bar{E}$ & \begin{tabular}{|c} 
Tensile \\
Stress \\
Area \\
\end{tabular} & $\begin{array}{l}\begin{array}{l}\text { Fastener } \\
\text { coating }\end{array} \\
\end{array}$ & $\begin{array}{c}\text { Bolt Torque \& } \\
\text { Clamp Load }\end{array}$ & $\begin{array}{c}10,000 \\
\text { psi }\end{array}$ & $\begin{array}{c}25,000 \\
\text { psi }\end{array}$ & $\begin{array}{l}\text { SAE J429- } \\
\text { Grade } 2\end{array}$ & $\begin{array}{l}\text { SAE J429- } \\
\text { Grade } 5\end{array}$ & $\begin{array}{l}\text { SAE J429- } \\
\text { Grade } 8\end{array}$ & $\begin{array}{l}\text { ASTM A574 } \\
\text { Socket Head } \\
\text { Cap Screw }\end{array}$ \\
\hline \multirow{4}{*}{$\begin{array}{l}3 / 8 \\
\text { UNC }\end{array}$} & \multirow{4}{*}{16} & \multirow{4}{*}{0.0775} & & Clamp Load (b) & 775 & $\begin{array}{ll}1,937 \\
\end{array}$ & 3,196 & 4,940 & 6,974 & 8,136 \\
\hline & & & Lubricated & \multirow{3}{*}{ Torque (F } & 4 & 9 & 15 & 23 & 33 & 38 \\
\hline & & & Zinc Plated & & 4 & 11 & 18 & 28 & 39 & 46 \\
\hline & & & Plain-Dry & & 5 & 12 & & & 44 & 51 \\
\hline \multirow{4}{*}{$\begin{array}{l}3 / 8 \\
\text { UNF }\end{array}$} & \multirow{4}{*}{240} & \multirow{4}{*}{0.0878} & & (bb) & \begin{tabular}{|l|}
878 \\
\end{tabular} & 2,196 & & & & 9,222 \\
\hline & & & & \multirow{3}{*}{ Torque (Ft-Lb) } & 4 & 10 & & & & 10 \\
\hline & & & Zinc Plated & & 5 & 12 & 20 & 31 & 44 & 52 \\
\hline & & & Plain - Dry & & 5 & 14 & & & & 58 \\
\hline \multirow{4}{*}{$\begin{array}{l}7 / 16 \\
\text { UNC }\end{array}$} & \multirow{4}{*}{140} & \multirow{4}{*}{.1063} & & Clamp Load (Lb) & 1,063 & 2,658 & 4,385 & $6, m$ & 9,568 & 11,162 \\
\hline & & & Lubricated & \multirow{3}{*}{ |Tor: } & 6 & 15 & 24 & $37,>3$ & 52 & 61 \\
\hline & & & Zinc Plated & & 7 & 17 & & & & 73 \\
\hline & & & Prain-Dry & & 8 & 19 & 32 & $49-2>>$ & 70 & 81 \\
\hline
\end{tabular}

The angle-controlled tightening method or the turn-to tighten method involves using a torqueing instrument to reach a relatively low torque specification and then to rotate the bolt a particular number of times or degrees, (based on predetermined values from testing trials), that ideally approaches the yielding point of the bolt. The torqueing instrument can be seen in Fig. 3.

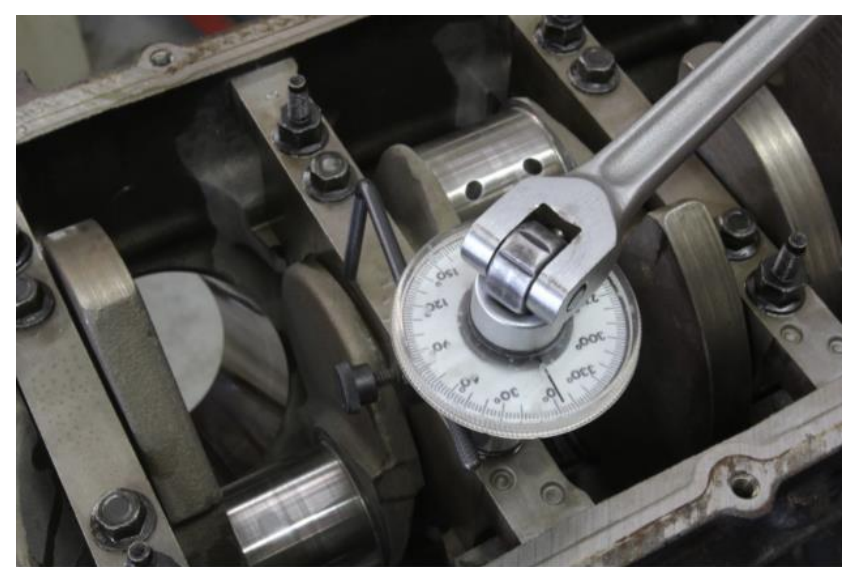

Fig. 3 Angle Controlled Tightening Method [4]

The yield-controlled tightening method is a much more technical approach to torqueing. It utilizes a control system that is sensitive to the torque and which indicates when the yield point has been reached, and then stops the tightening process. Fig. 4 shows the relationship between the clamping force and the angle of rotation. "When the bolt exceeds the yield clamp force is when the bolt is no longer tightened. The clamping force and rotation angle are no longer a linear relation indicating that the yield point has been reached. This is achieved by incorporating sensors to read torque and angle during the tightening process" [5]. This method can be considered a "tailored" approach, because sensors are used to consider the particular conditions of an individual bolt.

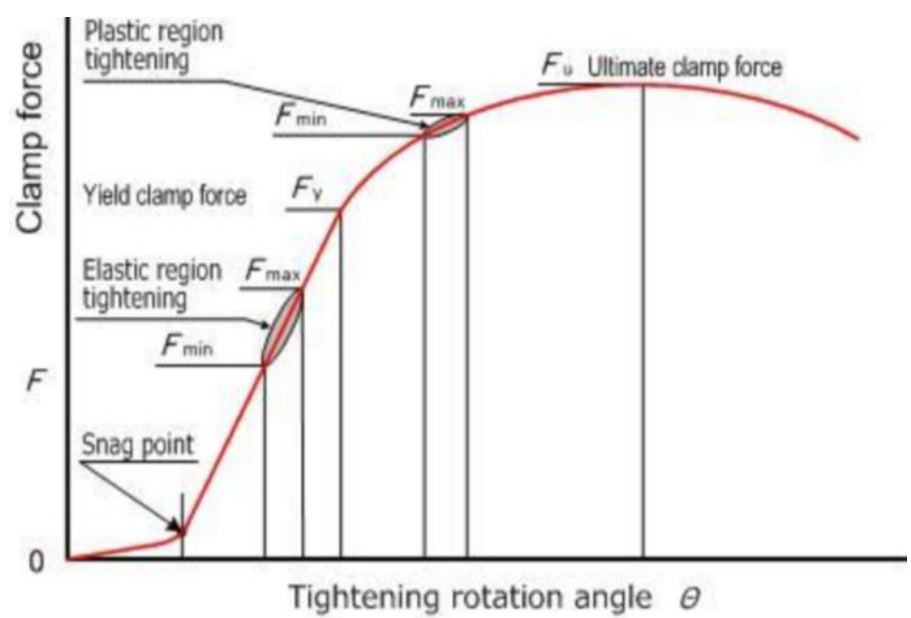

Fig. 4 Yield Controlled Tightening Method [6]

In the case of a military operation using an unmanned aircraft in Afghanistan, a malfunction that caused the crash of an air vehicle was determined to be caused by an improperly secured part. The article reads "Post-mishap analyses of inservice LRU-X-1 cap screws reflect a significant departure from required values of $18-22$ inch-pounds above prevailing torque," [7] reads the report. "Improper torque, insufficient use of thread locking compound or reuse of a deformed lock washer could allow cap screws to vibrate loose during flight operations" [7]. New maintenance procedures were 
immediately implemented for the remainder of the vehicles, in consideration of improperly torqued parts.

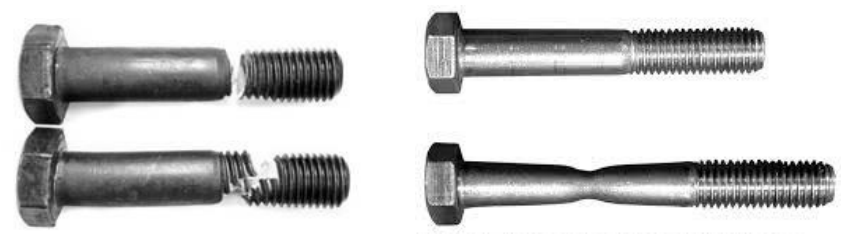

Fig.5 Bolt Fracture [8] (left), Plastic Deformation [9] (right)

\section{ENGINEERING REQUIREMENTS}

Creating a successful modular torque wrench extension with a heads-up display feature, the following characteristics must be met:

Simplicity - The modular torque wrench and heads-up display unit must be designed and programmed in a way that eases the operation of most of the control settings required in a manual torque wrench.

Reliability - Construction of the modular torque wrench and heads-up display unit must be robust enough to withstand daily use and impact forces, similar to a manually adjusted torque wrench. Furthermore, the modular torque wrench must maintain precise calibration in order to provide accurate torque readings to the user.

\section{PRELIMINARY Design Evaluation}

\section{A. Overview}

To implement a strain gauge into our design, it is necessary to understand how it functions. The strain gauge converts an applied force into a change in electrical resistance. The applied force can be a tensile force or a compressive force. Variations in resistance are dependent on the change in length of the strain gauge. With the change in length of the object in a particular direction, there are stress and strain forces involved which result in a change in electrical resistance of the strain gauge [10]. A strain gauge uses a Wheatstone Bridge circuit, which is responsible for converting the change in resistance into an equivalent voltage change. The Wheatstone Bridge circuit will use a stable DC power supply for excitation.

For this project, two strain gauges will be positioned at 45 degrees from the longitudinal axis and evenly on the midplane of the longitudinal, in order to place the sensor as far as possible from the location of the applied load. It is necessary to calibrate the sensor to develop the torque wrench extension. Conducting theoretical calculations and using a known reference standard for the material in use allows for accurate calibration of the gauge sensor to the applied force [11]. The toque sensing strain gauge that is to be used has been designed for static or reaction torque applications, since the torque wrench extension does not experience a high rpm application and deformation occurs within much less than one rotation of the strain gauge implementation.
Based on Von Mises theory, the shear strength of the wrench extension can be related to the tensile strength by (1).

$Y S S=\sqrt{3} Y T S$

YTS is the yield tensile strength of the material and YSS is the shear strength of the material. Using a yield tensile strength of $415 \mathrm{MPa}$ for 4140 steel [12], the yield shear strength of the material is found to be $240 \mathrm{MPa}$.

Next, to determine the allowable shear stress the wrench extension can perform under based on a specified factor of safety and the shear strength, (2) is used.

$$
\tau_{\text {all }}=\frac{Y S S}{F S}
$$

Where FS is the factor of safety, YSS is the yield shear strength of the material (in MPa), and $\tau_{\text {all }}$ is the allowable shear stress in (in MPa). Using an aerospace grade factor of safety of 1.5 and the yield shear strength of the material of $240 \mathrm{MPa}$, the allowable shear stress is found to be $160 \mathrm{MPa}$.

The maximum torque that can be applied can be calculated using (3).

$T=\frac{\tau_{\text {all }} \times J}{R}$

Where $\tau_{\text {all }}$ is the allowable shear stress in, $\mathrm{T}$ is the torque (in $\mathrm{N} \cdot \mathrm{m}$ ), $\mathrm{R}$ is the radius (in $\mathrm{m}$ ), and $\mathrm{J}$ is the polar moment of inertia (in $\mathrm{m} 4$ ).

Since the wrench extension that is used is a solid shaft, the polar moment of inertia, J, can be calculated using (4)

$$
J=\frac{\pi R^{4}}{2}
$$

Where $\mathbf{J}$ is the polar moment of inertia (in $\mathrm{m} 4$ ) and, $\mathrm{R}$ is the radius (in $\mathrm{m}$ ). Using a radius of $0.00615 \mathrm{~m}$ the polar moment of inertia is calculated to be $2.036 \times 10-9 \mathrm{~m} 4$. With the polar moment of inertia and an allowable shear stress of $160 \mathrm{MPa}$, the torque is found to be $58.46 \mathrm{~N} \cdot \mathrm{m}$.

Alternatively instead of using the yield tensile strength of the 4140-steel alloy, the ultimate tensile strength of $655 \mathrm{MPa}$ can be used. With this, the ultimate shear strength becomes 378.16 MPa. By applying a factor of safety of 1.7 the allowable shear stress becomes $222.45 \mathrm{MPa}$, which is below the yield shear strength previously determined; thus even by utilizing the ultimate shear strength of the material with a factor of safety of 1.7, the wrench extension will only undergo elastic deformation. By applying the same equation and calculations used previously, the maximum torque is found to be $81.27 \mathrm{~N} \cdot \mathrm{m}$.

The shear strain of the corresponding torque wrench extension is calculated using (5).

$\gamma=\frac{4 \times T(1+v)}{E \times \pi \times R^{3}}$

Where T is the torque (in N.m), $v$ is the Poisson's Ratio of the material, $\mathrm{R}$ is the radius of the torque wrench extension (in $\mathrm{m}$ ), and $\mathrm{E}$ is the elastic modulus of the material (in $\mathrm{Pa}$ ).

$1^{\text {th }}$ LACCEI International Multi-Conference for Engineering, Education, and Technology: "Modular Torque Wrench Extension with Heads-up Display", 29-31 July 2020, Bueno Aires, Argentina. 
Using the Wheatstone Bridge configuration with 2 strain gauges with a gauge factor of 2 and two known resisters with 1000-ohm resistance, equation (5) can be formulated into (6) to understand the output voltage at an applied torque value.

$\frac{V_{o}}{V}=\frac{G F \times T(1+v)}{E \times \pi \times R^{3}} \times 10^{3} \frac{m V}{V}$

Where $\mathrm{V}_{\mathrm{o}}$ is the output voltage (in $\mathrm{mV}$ ), $\mathrm{V}$ is the excitation voltage (in $\mathrm{mV}$ ), and GF is the gauge factor of the strain gage.

Using (6), with a GF of 2, R of $0.00615 \mathrm{~m}$, T of $81.27 \mathrm{~N} \cdot \mathrm{m}$, Poisson's ratio of 0.29, and an Elastic modulus of $205 \mathrm{GPa}$; the output voltage from the Wheatstone Bridge circuit is $1.4 \mathrm{mV}$ for every volt of excitation provided to the circuit.

\section{B. Mechanical Design}

The electronics and sensor used for measuring applied toque will be housed in a mechanical fixture that surrounds the shaft of the 3/8th inch extension. Similarly, electronics for the augmented reality lens are contained within a mechanical fixture that attaches to safety glasses. The conceptual design for the shaft housing and augmented reality lens housing can be seen in Fig. 5 and Fig. 6, respectively.

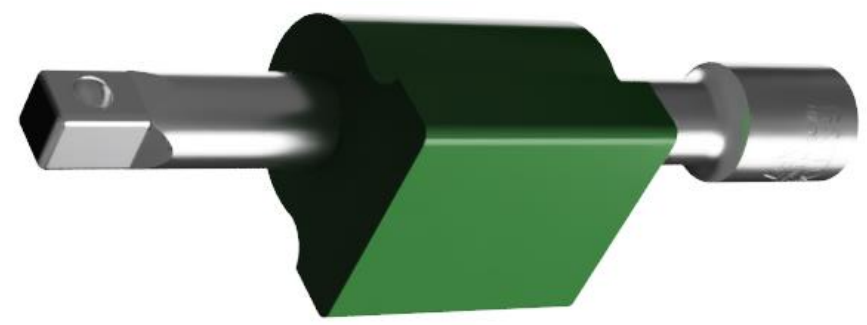

Fig.6 3/8th inch Shaft Electronics Housing

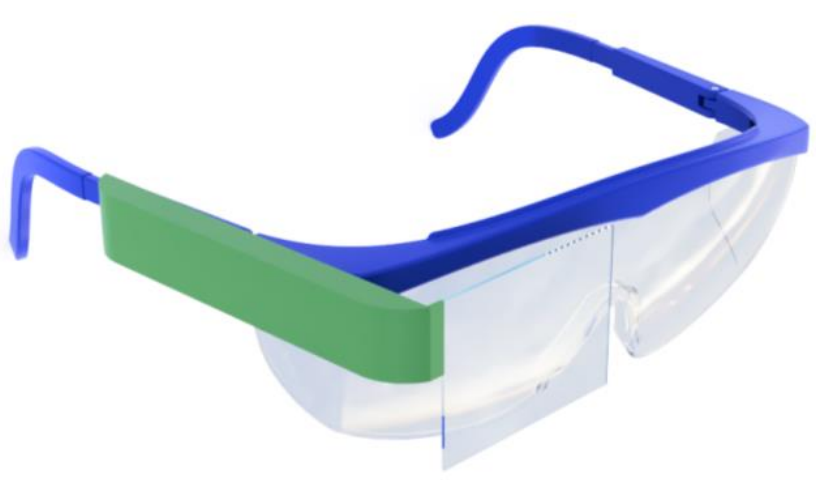

Fig.7 Heads-up Display Housing

\section{Electrical System Design}

For the proposed system to fully operate, the following electrical diagrams are adopted, shown in Fig. 8 and Fig. 10.

Fig. 8 represent the electrical schematic for the torque sensor, consisting of an Arduino Nano, XBEE transmitter module, HX711 load cell amplifier, two strain gauges, and two resistors.

Fig. 10 represents the electrical schematic for the augmented reality lens, consisting of an Arduino Nano, an organic light-emitting diode (OLED) display, and an XBEE receiver module.

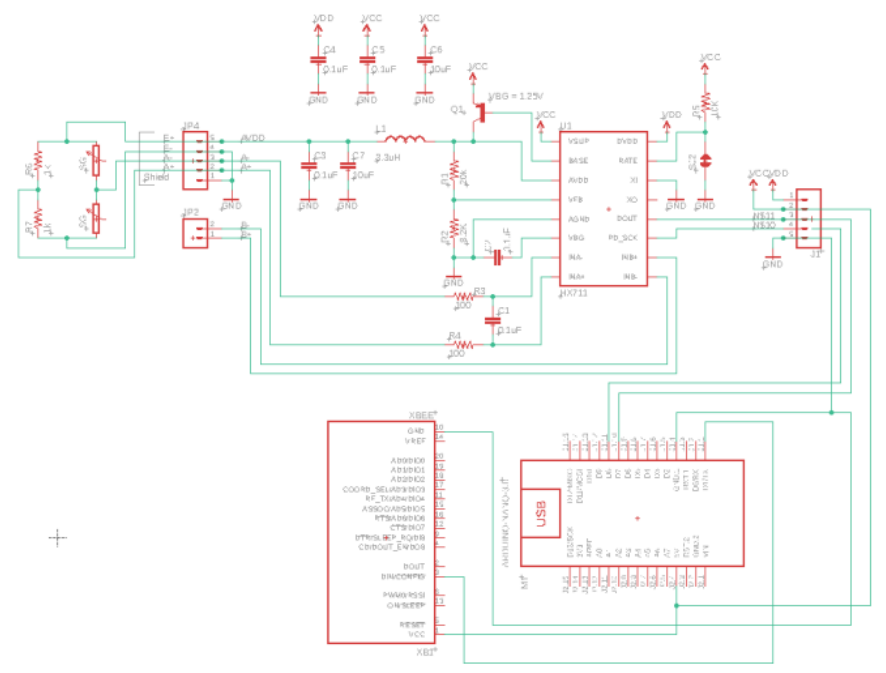

Fig.8 Torque Wrench Extension Electrical System

The HX711 connects to the Arduino Nano using four connections; VCC, GND, DOUT, and PD_SCK. The VCC and GND are used to power the HX711 load cell amplifier module from the Arduino Nano, whereas, the DOUT and PD_SCK (Data and clock) allow for a two-wire interface for communication. The left portion of the HX711 module consists of the Excitation and Amplifier, which is connected to the strain gauges. A closer look at the strain gauge wiring can be seen in Fig. 9.

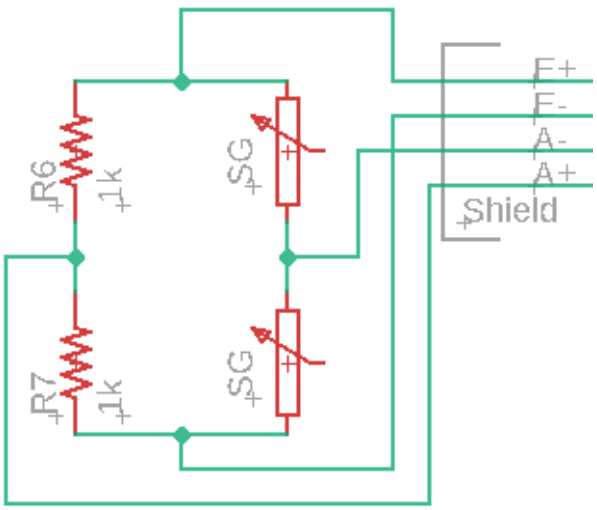

Fig.9 Wheatstone Bridge Configuration

The HX711 module connects to two 1000-ohm resistors and 2 strain gauges. These components are connected in a Wheatstone Bridge configuration. The Wheatstone Bridge allows us to measure an unknown resistance value by maintaining a balance between two circuit legs. In our case, we want to obtain the changing resistance values, as the torque is applied to measure the voltage change. To achieve this, the excitation ( + and -$)$ are connected in between the known resistor and the strain gauge. The amplifier (+) is connected between the two known resistors, and the amplifier (-) is connected in between the two strain gauges. The excitation from the HC711

$18^{\text {th }}$ LACCEI International Multi-Conference for Engineering, Education, and Technology: "Modular Torque Wrench Extension with Heads-up Display”, 29-31 July 2020, Bueno Aires, Argentina. 
module provides the Wheatstone Bridge with $4.08 \mathrm{~V}$, and the amplifier measures the voltage change.

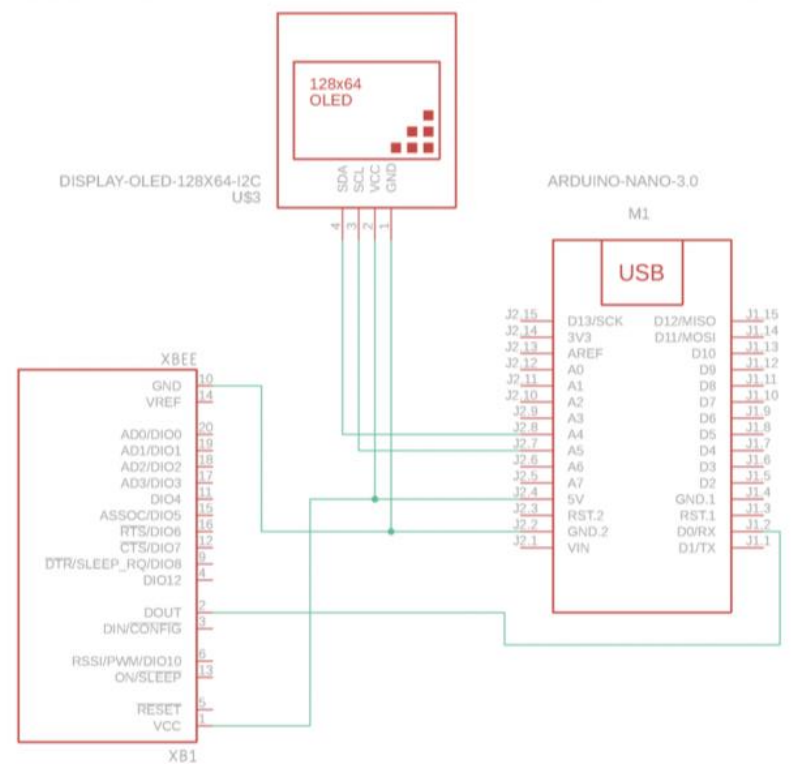

Fig.10 Heads Up Display Electrical System

\section{PROTOTYPE}

\section{A. Communication}

The communications aspect of the torque wrench extension with heads-up display is based on the transmission of data from one Arduino Nano to another. The project entails using wireless communication to create simplicity for the end-user and to reduce any restriction in mobility of its user. To enable wireless communication between the Arduinos, two XBee S2C modules are used. The XBee S2C modules have antennas that operate at a programmable frequency. In addition to the communication modules, the OLED display is used for confirming that data is being transmitted from one XBee S2C to the other.

The connectivity status of the Arduino Nanos was then determined by powering on the Nano using a USB Type-A male cable to a USB Mini male. The power supply was the computer used for programming the Arduino and its modules. The OLED display was supplied with $3.3 \mathrm{~V}$ from the Arduino Nano. The Xbee $\mathrm{S} 2 \mathrm{C}$ was powered using the $5 \mathrm{~V}$ pin from the Ardiuno Nano. To test the Xbee S2C modules, they were connected to an XBee USB Adapter Board that allows for direct interaction of the XBee S2C and the computer used to program the communication module. Both XBee's were connected to the computer at the same time and set up on XCTU, the chosen radio frequency communication platform for programming the XBee S2C's was set. The communications parameters were adjusted to enable communication in a point to point communication manner. The emitter was labeled "Coordinator" and the Receiver was labeled as "Router".

After programming the communication parameters, we needed to prove that the modules are, in fact, able to transmit data. By using the XCTU software and the terminal tab, serial data can be transmitted out from one module at a time and by switching to another module any received data can be observed [13].

\section{B. Torque Wrench}

To properly obtain an applied torque value from the torque wrench, it must be fitted with a strain gauge. As a load is applied the strain gauge's resistance changes, with this change in resistance we can measure the torque that is applied by the user and display it on the headset.

Due to possible contamination, the process of applying the strain gauge onto the torque wrench extension is an extremely complex and delicate procedure. Any foreign debris, including oil excretions from the user's hand, can negatively impact the reading obtained by the strain gauge.

To begin the stain gauge application process, the surface of the torque wrench extension was sanded using 320-grit siliconcarbide paper, where the strain gauge would be applied. This allows the gauge to properly adhere to the surface. Next, MPrep Conditioner A is applied to the surface and slowly wiped through the surface using a gauze sponge. M-Prep Conditioner $\mathrm{A}$ is a mild phosphoric-acid compound acting as a mild etchant, while accelerating the cleaning process. The M-Prep Conditioner $\mathrm{A}$ is followed by M-Prep Neutralizer 5A. The surface is scrubbed using a cotton swab. With a single wiping motion, the area is cleaned again using a gauze sponge to prevent the re-deposition of contaminants. A pencil is used to mark the surface, ensuring the stain gauge is correctly centered.

After the surface is prepped, the strain gauge is removed from its packaging using tweezers and placed onto the torque wrench extension using the previously marked areas as guides. A single piece of tape is placed over the gauge and rolled back slowly at a 45-degree angle to bring up the gauge with tape. The tape is pulled back far enough, so the specimen is lifted, but a portion of the tape is still attached to the torque wrench extension. Next, a single bead of Loctite 496 is placed on the torque wrench extension, right below the tape and specimen. The tape is rolled onto the surface using a single motion. Immediately after, firm thumb pressure is applied to the gage and terminal area for roughly 5 minutes. This allows proper bonding while also accelerating curing time, due to heat generation from the user's finger. Finally, after 24-hours of cure time, the tape is removed. The surface is inspected, and any excessive adhesive is wiped using isopropyl alcohol [14].

All the components used during the strain gauge application process can be seen in Fig. 11 and the torque wrench extension with the applied strain gauge can be seen in Fig. 12.

$1^{\text {th }}$ LACCEI International Multi-Conference for Engineering, Education, and Technology: "Modular Torque Wrench Extension with Heads-up Display”, 29-31 July 2020, Bueno Aires, Argentina. 


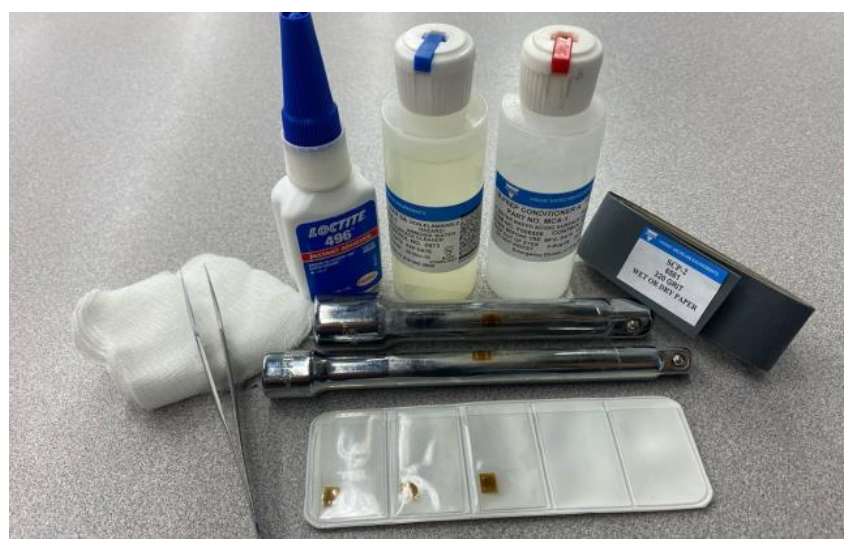

Fig.11 Torque Wrench Strain Gage Assembly Kit

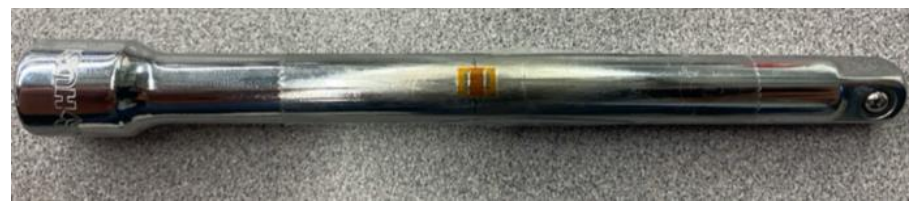

Fig.12 Torque Wrench with Strain Gage

After the electrical components are successfully wired to the strain gauge, the Arduino Nano is programmed using Arduino Integrated Development Environment (IDE). Arduino IDE, a cross-platform application, allows users to write functions in $\mathrm{C}$ and $\mathrm{C}++$. Once the program is written and debugged, users can upload it to a compatible microcontroller within the IDE. The program used for testing the torque wrench extension can be seen in Fig. 13.

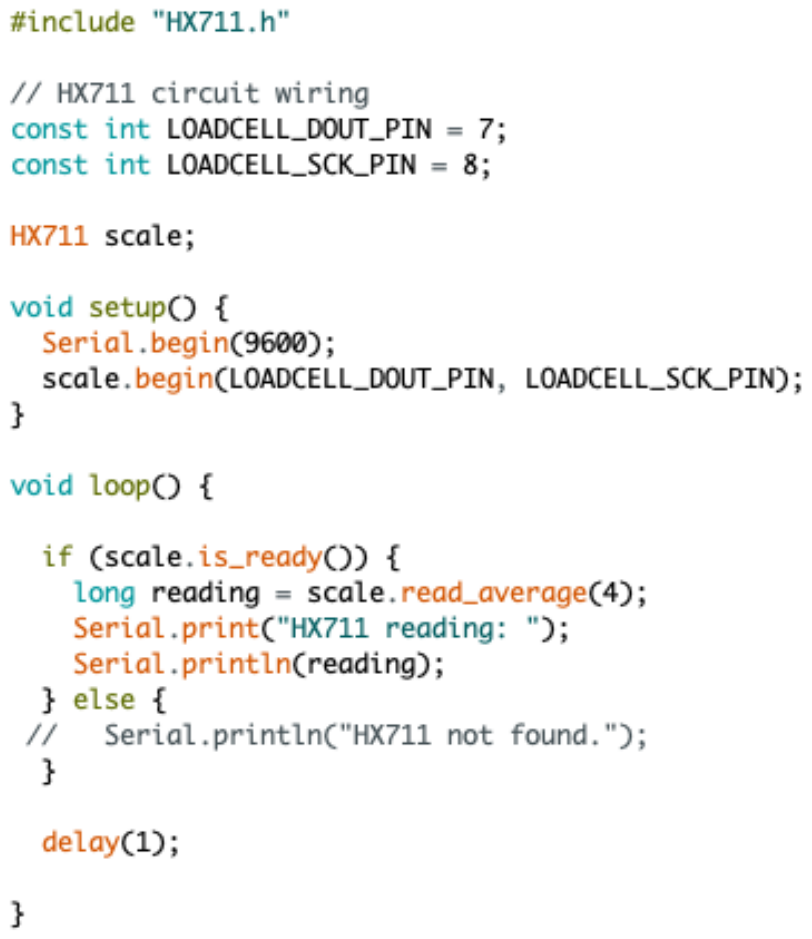

Fig.13 Torque Wrench Program
To begin the code, the HX711 header file is included in the code. The header file contains definitions for the HX711 library, which includes commands (functions) and needed variables. Next, the data and clock pins previously connected from the HX711 module to the Arduino Nano are declared with their corresponding general-purpose input/output pin. Within the main program loop, readings from the strain gauge circuit are taken. The code reads four measurements and averages them, before displaying it to the user to provide a steady baseline. After the code is uploaded to the Arduino Nano, using the serial monitor function within the Arduino IDE, the fluctuations, as torque is applied, can be graphed and displayed to the user. The graphed data read by the HX711 module can be seen in Fig. 14.

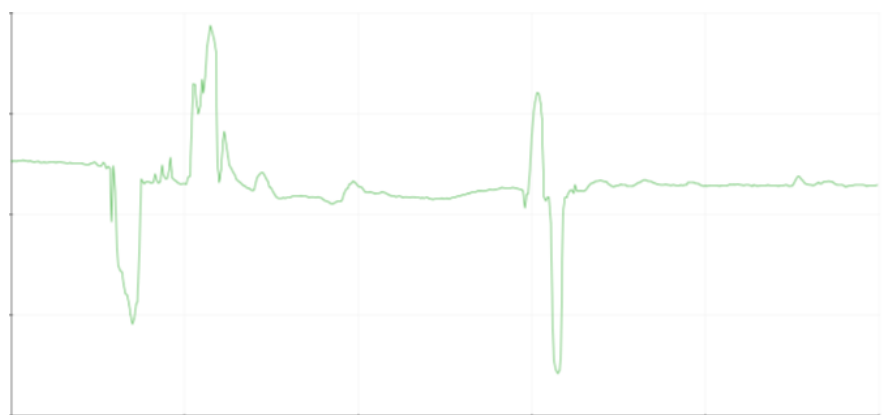

Fig.14 Arduino Strain Output

An observation of the serial monitor graph of the HX711 module reveals 4 large spikes from the baseline reading. Two large upward spikes show that torque was applied to the wrench extension in a clockwise direction; whereas, two large downward spikes indicate that torque was applied to the wrench extension in a counterclockwise direction.

\section{Headset}

The Headset works by using different methods to deliver the screen's output to the user. The principal method is reflection. According to the law of reflection, in the case of specular surfaces (Mirror-like) the angle at which the light wave hits the surface will be equal to the angle at which it is reflected. Inside the headset, there will be a small and thin mirror providing one of the most common models for specular light reflection.

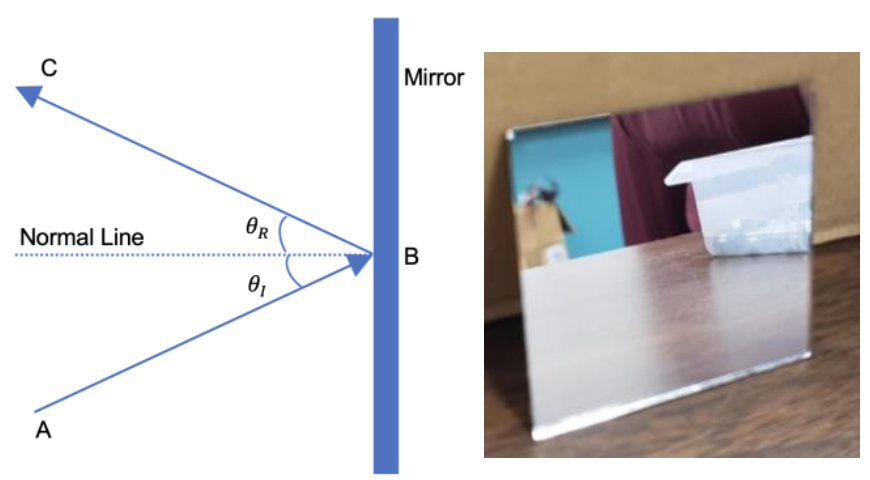

$1^{\text {th }}$ LACCEI International Multi-Conference for Engineering, Education, and Technology: "Modular Torque Wrench Extension with Heads-up Display”, 29-31 July 2020, Bueno Aires, Argentina. 
Fig. 15 Reflection on Specular Faces

In Diagram Fig. 15, a light ray $\mathrm{AB}$ strikes a vertical mirror at point $\mathrm{B}$, and the reflected ray is $\mathrm{BC}$. By projecting an imaginary line through point $\mathrm{O}$ perpendicular to the mirror, known as the normal, we can measure the angle of incidence, $\theta \mathrm{i}$ and the angle of reflection, $\theta$ r. As stated before, $\theta i=\theta r$, the angle of incidence equals the angle of reflection. Using these formulas, it is possible to formulate the angle of incidence for the headset, which is 45 degrees, since the normal line of the mirror is set to also be at 45 degrees from the input OLED screen. This procedure will output a reflection at an exact angle of 90 degrees from the OLED display.

Once a reflection is obtained, a new problem is presented, since the reflection would be a flipped image from what the OLED is outputting. For this reason, a focal lens will be placed after the reflection from the mirror on the headset. The lens used on the headset is a Biconvex focal lens, which is composed of two convex surfaces in spherical form. Usually these surfaces have the same radius of curvature. This type of lens is also referenced as a convex-convex lens.

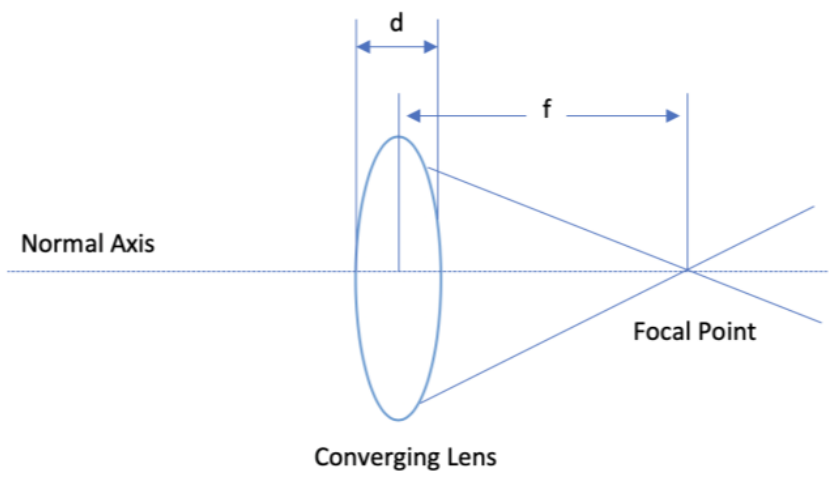

Fig.16 Bi-convex Lens Characteristics

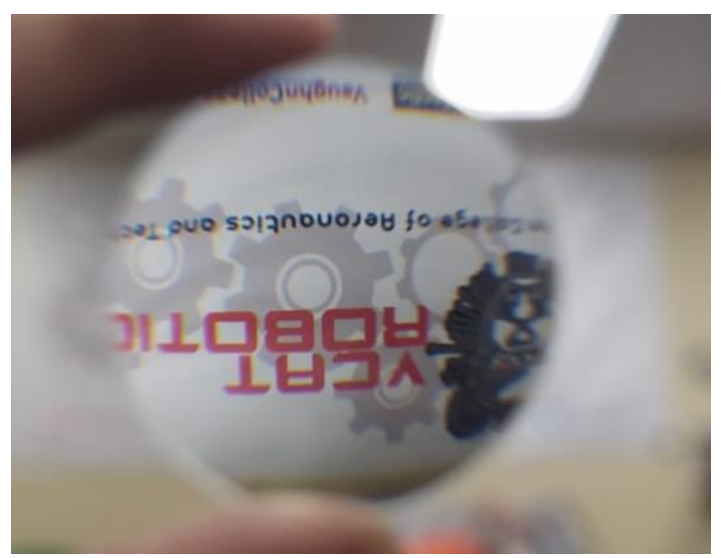

Fig. 17 Physical Representation of Light Through Biconvex Lens

In a biconvex lens, a beam of light passes through the lens and converges at a specific point or focus after the lens, as in Fig. 16. The distance between the lens and this focused point is referenced as the focal length of the lens. Since there is a curvature on both sides of the lens, there will be two focal points and two centers, which helps to invert the beams of light from one side to the other. A 100-millimeter focal lens is used, so that the lens takes the inverted light coming from the mirror and reverts it, Fig. 17 [14]. The focal lens along with the mirror is enclosed within a 3D printed housing shown in Fig. 18.

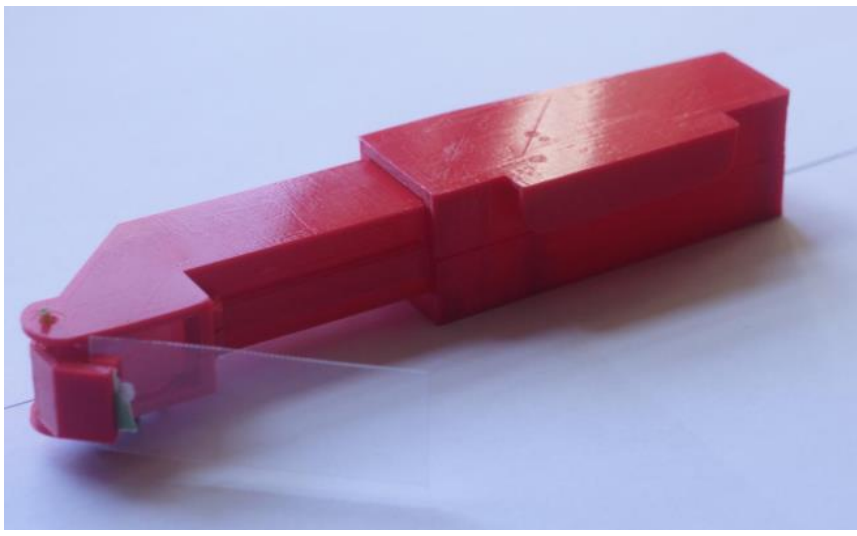

Fig. 18 Headset Prototype

\section{IMPACTS}

\section{A. Social Impacts}

A device that eases the manufacturing process may be perceived as a risk, since such devices may be seen as reducing the concentration required to assemble structures. Technicians must be attentive to their process. However, there is no benefit in attentiveness to be gained by having technicians continually set their torque wrench between each bolt and shift. By simply eliminating the tedious task of setting a torque wrench, the device assures a consistent and reliable torque that does not detract from the assembler's attention. Rather, their concentration will increase, since the glasses provide meaningful feedback to ensure the technician's engagement in his or her work.

\section{B. Economic Impacts}

This innovative device provides companies with savings on monthly calibrations, including material processing, paperwork completion, and shipping. Also, the use of this device ensures high reliability in the torqueing of hardware/fasteners. For instance, both maintenance time and costs are reduced by the time technicians spend on the completion of this task. Further, companies are no longer required to deal with the over-torque of hardware that can lead to the removal and replacement of expensive components.

\section{Environmental Impacts}

This device eliminates the need for manuals used to find the specific torque of any hardware/fasteners. Companies are therefore no longer required to print a hard copy of manuals or references for technicians to complete their assigned tasks. This device is thus eco-friendly by contributing to the prevention of air, water, and land pollution. This sophisticated device also reduces, or even eliminates, the common problem

$1^{\text {th }}$ LACCEI International Multi-Conference for Engineering, Education, and Technology: "Modular Torque Wrench Extension with Heads-up Display”, 29-31 July 2020, Bueno Aires, Argentina. 
of over-torqueing hardware which then becomes a wasted resource which companies must dispose into the environment.

\section{CONCLUSION}

The need for safe, reliable, precise, and accessible equipment is continually on the rise. Cutting-edge industries, such as Aviation, have extremely high technical standards offering little to no compromise in safety. By bridging the gap between technological advancements and conventional bolt torqueing methods, a more favorable product can be designed. This project aims to meet those standards by offering a product that meets the demand for quality manufactured and overhauled parts. The implementation of the torque wrench extension with heads-up display in bolt-torqueing related applications significantly improves technical operations and accelerates product output without disrupting current operation methods. Simple workflow integration, with minimal downtime for effective machine use, is accomplished with the modular torque wrench extension and heads-up display, as seen in Fig. 19.

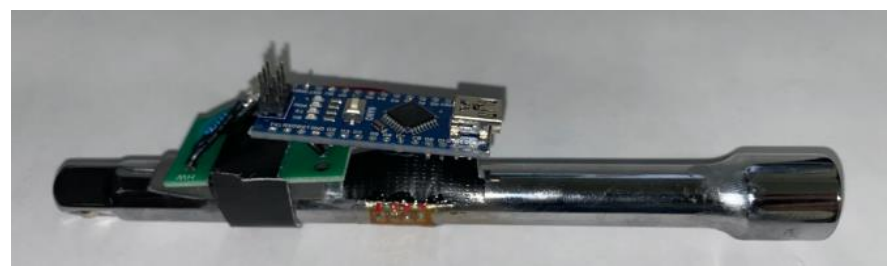

Fig. 19 Complete Modular Torque Wrench (No Casing)

\section{ACKNOWLEDGMENT}

The authors would like to thank the President of Vaughn College of Aeronautics and Technology, Dr. Sharon DeVivo, along with the Engineering Department for their continued support. Also, special thank you to Dr. Mohammed Benalla, Dr. Hossein Rahemi, Dr. Margaret Ducharme, and Donald Jimmo for their continuous support and guidance throughout this project.

\section{REFERENCES}

[1] Zarzyczny, Ruby. "Making an Engine Change in the Desert." U.S. Air Force, 28 Nov. 2007, www.af.mil/News/ArticleDisplay/Article/125019/making-an-engine-change-in-the-desert/.

[2] Gribble, Jim. "What Is the Nut Factor and How Does It Affect Torque?" SmartBolts, SmartBolts, 5 Jan. 2017, www.smartbolts.com/insights/nutfactor-affect-torque/.

[3] "Bolt Torque Chart." Industrial Repair Information, Tips and Resources, www.repairengineering.com/bolt-torque-chart.html.

[4] Smith, Jeff. "Ask Away! with Jeff Smith: The Truth Behind Torque-toYield Fasteners and Torque Angle Fastening." OnAllCylinders, 11 May 2018, www.onallcylinders.com/2016/08/19/ask-away-jeff-smith-truthbehind-torque-yield-fasteners-torque-angle-fastening/.

[5] "Methods of Tightening Threaded Fasteners." Bolt Science, www.boltscience.com/pages/tighten.htm.

[6] "Vol.7 Screw Tightening Control Methods: NBK: Couplings, Screws, Clampers." NBK, www.nbk1560.com/en-US/products/specialscrew/ nedzicom/topics/07_torque_management/.

[7] Rosenberg, Zach. "Loose Wire Caused Afghanistan Global Hawk Crash." Flight Global, 7 Mar. 2012, www.flightglobal.com/news/articles/loosewire-caused-afghanistan-global-hawk-crash-369238/.
[8] "Bolt Joint Design." Fastenal, Fastenal Engineering and Design Support, www.fastenal.com/content/feds/pdf/Article\%20-\%20Bolted\%20Joint $\% 20$ Design.pdf.

[9] Saliby, Fadi. "6 Types of Bolt Failure and How to Prevent It - Proven Productivity." Bossard Proven Productivity, 8 Aug. 2017, provenproductivity.com/6-types-bolt-failure-prevent/.

[10] "Torque Transducers \& Torque Sensors: UK Supplier." Applied Measurements Ltd, appmeas.co.uk/products/torque-sensors/.

[11] "What Is a Strain Gauge." Omega Engineering, www.omega.co.uk/prodinfo/StrainGauges.html.

[12] “AISI 4140 Alloy Steel (UNS G41400).” AZoM.com, 18 Dec. 2019, www.azom.com/article.aspx?ArticleID=6769.

[13] "Arduino Wireless Shield S2." Arduino, www.arduino.cc/en/Guide/ArduinoWirelessShieldS2

[14] "Instruction Bulletin B-127." Micro Measurment a VPG Brand, 12 Feb. 2018.

[15] Lekner, John. Theory of Reflection: of Electromagnetic and Particle Waves. M. Nijhoff, 1987.

$1^{\text {th }}$ LACCEI International Multi-Conference for Engineering, Education, and Technology: "Modular Torque Wrench Extension with Heads-up Display”, 29-31 July 2020, Bueno Aires, Argentina. 